Pacific Journal of Mathematics

OWL ERA 


\title{
COUNTEREXAMPLES TO A CONJECTURE OF G. N. DE OLIVEIRA
}

\author{
D. J. HARTFIEL
}

\begin{abstract}
G. N. de Oliveira gives the following conjecture. CONJECTURE. Let $\mathbf{A}$ be an $\mathbf{n} \times \mathbf{n}$ doubly stochastic irreducible matrix. If $n$ is even, then $f(z)=$ perm $(I z-A)$ has no real roots; if $n$ is odd, then $f(z)=$ perm $(I z-A)$ has one and only one real root.
\end{abstract}

In this paper we give counter examples to this conjecture.

Results :

EXAMPLE 1. Let

$$
A=\left[\begin{array}{lll}
\frac{1}{2} & \frac{1}{2} & 0 \\
\frac{1}{2} & \frac{1}{4} & \frac{1}{4} \\
0 & \frac{1}{4} & \frac{3}{4}
\end{array}\right] .
$$

$f(z)=\operatorname{perm}(I z-A)$ is such that $f(0)<0$ and $f(1)>0$. Consider $f(z) \cdot(z-1)=g(z)$. Note that $g(0)>0$ and since there is a $\xi\{0<\xi<$ 1) for which $f(\xi)>0$ we see that $g(\xi)<0$. Now consider

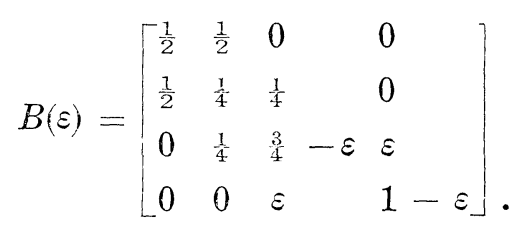

If $0 \leqq \varepsilon \leqq \frac{3}{4}, B(\varepsilon)$ is doubly stochastic. Further if $g_{s}(z)=$ perm $[I z-B(\varepsilon)]$ then for each $z, g(z)=\lim _{i \rightarrow 0} g_{i}(z)$. Since $g_{\varepsilon}(0)>0$ for each $\varepsilon$ and $g(\xi)=\lim _{\varepsilon \rightarrow 0} g_{s}(\xi)<0$ we see that for sufficiently small $\varepsilon$, say $\varepsilon_{0}, g_{c_{0}}(z)$ has a real root and $B\left(\varepsilon_{0}\right)$ is irreducible. This yields the counter-example. Note also that $g_{\varepsilon_{0}}(z)>0$ for $z>1$ [see 1], hence $g_{\varepsilon_{0}}(z)$ has at least two real roots. Recall

EXAMPle 2. For simplification let $B\left(\varepsilon_{0}\right)=B$ and $g_{s_{0}}(z)=g(z)$.
(a) $g(0)>0$ and
(b) $g(\xi)<0$. By direct calculation we see that
(c) $g(1)>0$ and hence for some $\eta, \xi<\eta<1$
(d) $g(\eta)>0$.

Now consider $f(z)=g(z) \cdot(z-1)$. Note that

(a) $f(0)<0$

(b) $f(\xi)>0$ 
(c) $f(1)=0$

(d) $f(\eta)<0$.

Consider

$$
A(\varepsilon)=\left[\begin{array}{cccll}
\frac{-1}{2} & \frac{1}{2} & 0 & 0 & 0 \\
\frac{1}{2} & \frac{1}{4} & \frac{1}{4} & 0 & 0 \\
0 & \frac{1}{4} & \frac{3}{4}-\varepsilon_{0} & \varepsilon_{0} & 0 \\
0 & 0 & \varepsilon_{0} & 1-\varepsilon_{0}-\varepsilon & \varepsilon \\
0 & 0 & 0 & \varepsilon & 1-\varepsilon
\end{array}\right]
$$

where $0<\varepsilon<1-\varepsilon_{0}$.

Let $f_{\varepsilon}(z)=\operatorname{perm}[I z-A(\varepsilon)]$. Note that for each $z, \lim _{\varepsilon \rightarrow 0} f_{\varepsilon}(z)=f(z)$. Therefore for $\varepsilon$ sufficiently small, say $\varepsilon_{1}$
(a) $f_{\varepsilon_{1}}(0)<0$
(b) $f_{\varepsilon_{1}}(\xi)>0$
(c) $f_{\varepsilon_{1}}(\eta)<0$

(d) $f_{\varepsilon_{1}}(z)>0$ for $z>1$. Further $A\left(\varepsilon_{1}\right)$ is doubly stochastic and irreducible. Hence $f_{\varepsilon_{1}}(z)$ has at least three real roots. This yields a counter-example to the conjecture in the case $n$ is odd.

\section{REFERENCES}

1. R. A. Brualdi, and M. Newman, Proof of a Permanental Inequality, Quarterly Journal of Mathematics, Oxford (2), 17 (1966), 234-238.

2. G. N. De Oliveira, A Conjecture and Some Problems on Permanents, Pacific J. Math., 32, No 2, (1970), 495-499.

Received July 10, 1970.

TeXas A AND M University 


\section{PACIFIC JOURNAL OF MATHEMATICS}

\section{EDITORS}

H. SAMELSON

Stanford University

Stanford, California 94305

C. R. Hовву

University of Washington

Seattle, Washington 98105
J. DUGUNDJI

Department of Mathematics

University of Southern California

Los Angeles, California 90007

RICHARD ARENS

University of California

Los Angeles, California 90024

\section{ASSOCIATE EDITORS}
E. F. BECKENBACH
B. H. NeumanN
F. WOLF
K. YoSHIDA

\section{SUPPORTING INSTITUTIONS}

UNIVERSITY OF BRITISH COLUMBIA

CALIFORNIA INSTITUTE OF TECHNOLOGY

UNIVERSITY OF CALIFORNIA

MONTANA STATE UNIVERSITY

UNIVERSITY OF NEVADA

NEW MEXICO STATE UNIVERSITY

OREGON STATE UNIVERSITY

UNIVERSITY OF OREGON

OSAKA UNIVERSITY

UNIVERSITY OF SOUTHERN CALIFORNIA
STANFORD UNIVERSITY

UNIVERSITY OF TOKYO

UNIVERSITY OF UTAH

WASHINGTON STATE UNIVERSITY

UNIVERSITY OF WASHINGTON

AMERICAN MATHEMATICAL SOCIETY CHEVRON RESEARCH CORPORATION NAVAL WEAPONS CENTER 


\section{Pacific Journal of Mathematics}

\section{Vol. 38, No. $1 \quad$ March, 1971}

Bruce Alan Barnes, Banach algebras which are ideals in a Banach algebra ..... 1

David W. Boyd, Inequalities for positive integral operators............... 9

Lawrence Gerald Brown, Note on the open mapping theorem .............. 25

Stephen Daniel Comer, Representations by algebras of sections over Boolean

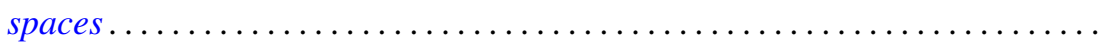

John R. Edwards and Stanley G. Wayment, On the nonequivalence of

conservative Hausdorff methods and Hausdorff moment sequences ........

P. D. T. A. Elliott, On the limiting distribution of additive functions $(\bmod 1) \ldots \ldots$

Mary Rodriguez Embry, Classifying special operators by means of subsets

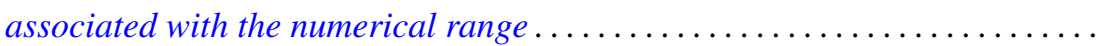

Darald Joe Hartfiel, Counterexamples to a conjecture of G. N. de Oliveira ......

C. Ward Henson, A family of countable homogeneous graphs...............

Satoru Igari and Shigehiko Kuratsubo, A sufficient condition for

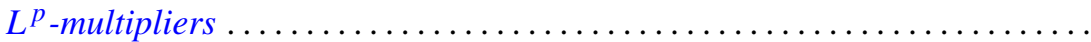

William A. Kirk, Fixed point theorems for nonlinear nonexpansive and

generalized contraction mappings............................

Erwin Kleinfeld, A generalization of commutative and associative rings ...... 95

D. B. Lahiri, Some restricted partition functions. Congruences modulo $11 \ldots \ldots 103$

T. Y. Lin, Homological algebra of stable homotopy ring $\pi *$ of spheres ....... 117

Morris Marden, A representation for the logarithmic derivative of a meromorphic function...........................

John Charles Nichols and James C. Smith, Examples concerning sum properties for metric-dependent dimension functions . .

Asit Baran Raha, On completely Hausdorff-completion of a completely

Hausdorff space.

M. Rajagopalan and Bertram Manuel Schreiber, Ergodic automorphisms and affine transformations of locally compact groups..........

N. V. Rao and Ashoke Kumar Roy, Linear isometries of some function

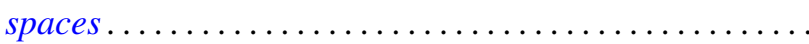

William Francis Reynolds, Blocks and F-class algebras of finite groups

Richard Rochberg, Which linear maps of the disk algebra are multiplicative ...

Gary Sampson, Sharp estimates of convolution transforms in terms of decreasing

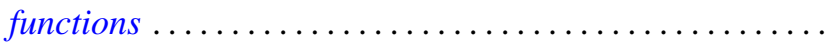

Stephen Scheinberg, Fatou's lemma in normed linear spaces

Ken Shaw, Whittaker constants for entire functions of several complex

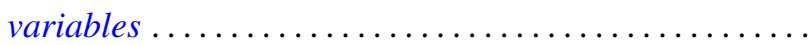

James DeWitt Stein, Two uniform boundedness theorems................ 251

$\mathrm{Li} \mathrm{Pi} \mathrm{Su,} \mathrm{Homomorphisms} \mathrm{of} \mathrm{near-rings} \mathrm{of} \mathrm{continuous} \mathrm{functions} \mathrm{.} \mathrm{.............} 261$

Stephen Willard, Functionally compact spaces, $C$-compact spaces and mappings of minimal Hausdorff spaces....................... 